\title{
Entre muros, pontes e fronteiras: teorias e epistemologias bissexuais
}

Helena Monaco ${ }^{1}$

Universidade Federal de Santa Catarina

Resumo: O artigo tem o objetivo de apresentar uma revisão de algumas das principais teorizações da bissexualidade, com foco naquelas produzidas a partir dos anos 1980. São discutidas algumas das chamadas epistemologias bissexuais, bem como perspectivas que entendem a bissexualidade como uma posição de fronteira entre as categorias homo e heterossexualidade. A partir dos argumentos expostos, concluo que a bissexualidade não estabeleceu um espaço próprio, mas circula pelos demais, ainda que como um outro incômodo.

Palavras-chave: bissexualidade; gênero e sexualidade; epistemologias bissexuais.

${ }^{1}$ Doutoranda e mestra (2020) em Antropologia Social pela Universidade Federal de Santa Catarina (UFSC). Possui bacharelado (2017) e licenciatura (2018) em Ciências Sociais pela UFSC. Integrante do Núcleo de Antropologia do Contemporâneo (TRANSES - PPGAS/UFSC) e do Grupo Amazônida de Estudos sobre Bissexualidade (GAEBI). Tem experiência na área de Antropologia, com ênfase em Gênero e Sexualidade, atuando principalmente nos seguintes temas: gênero, sexualidade, corpo, subjetividades, antropologia digital, bissexualidade e monodissidências. 


\title{
Between fences, bridges, and borderlands: Bisexual theories and epistemologies
}

\begin{abstract}
The article aims to present a review of some of the main theories of bisexuality, especially those produced since 1980 . It discusses some of the so-called bisexual epistemologies, in addition to some theories that understand bisexuality as a border between homosexuality and heterosexuality. Based on the arguments presented, the article concludes that bisexuality has not established its own space; it moves through other spaces while remaining an inconvenient other.
\end{abstract}

Keywords: bisexuality; gender and sexuality; bisexual epistemologies.

\section{Entre muros, puentes y fronteras: Teorías y epistemologías bisexuales}

\begin{abstract}
Resumen: El artículo tiene como objetivo presentar una revisión de algunas de las principales teorías de la bisexualidad, centrándose en las producidas desde la década de 1980. Se discuten algunas de las denominadas epistemologías bisexuales, así como perspectivas que entienden la bisexualidad como una posición de frontera entre las categorías homo y heterosexualidad. Basado en los argumentos expuestos, concluyo que la bisexualidad no ha establecido un espacio propio, sino que circula entre otros, aunque sea como un otro incómodo.
\end{abstract}

Palabras clave: bisexualidad; género y sexualidad; epistemologías bisexuales. 
$\mathrm{O}$ presente artigo tem o objetivo de apresentar uma revisão de algumas das principais teorizações da bissexualidade, com foco naquelas produzidas a partir dos anos 1980, influenciadas pela emergência dos principais movimentos bissexuais nos Estados Unidos e alguns países da Europa ao longo da década anterior ${ }^{2}$. Não se trata de uma revisão bibliográfica exaustiva sobre o tema ou de uma análise quantitativa das produções acadêmicas sobre bissexualidade, mas de uma introdução a algumas das mais influentes abordagens teóricas da bissexualidade, que permanecem relevantes até a atualidade.

Embora pouco conhecida no Brasil, existe uma produção acadêmica sobre bissexualidade ampla e diversa. Entretanto, grande parte desses trabalhos foi produzida no chamado norte global e não é traduzida para o português ou encontrada facilmente no país. De fato, apesar de crescente, a produção acadêmica sobre bissexualidade no Brasil ainda é escassa.

Por esse motivo, é comum, quando se fala de bissexualidade na academia, ouvir que são feitas poucas pesquisas, poucas reflexões e que há uma escassez de referências sobre o tema. Entretanto, a bissexualidade vem sendo objeto de diversas reflexões teóricas, num campo multidisciplinar, já há algum tempo. É verdade, como afirma Merl Storr (2002), que a ideia de ausência de literatura sobre bissexualidade é um equívoco, mas é preciso ter em conta que o acesso a esse material no Brasil é muito difícil. Isso porque não há traduções, os livros raramente estão disponíveis para consulta em bibliotecas ou para compra em livrarias nacionais e não há divulgação ou reconhecimento por pesquisadores de outras áreas. De fato, tenho percebido, em diálogo com outras pesquisadoras e pesquisadores brasileiros, que as discussões sobre bissexualidade estão ausentes em cursos das mais diversas áreas, como ciências sociais, antropologia, história e psicologia, mesmo em disciplinas voltadas a gênero e sexualidade3.

A ideia mesma de escassez de trabalhos sobre bissexualidade é sintomática da falta de disseminação deles, da ausência quase total de referências a esses trabalhos nas produções sobre homossexualidade, lesbianidade, feminismo, estudos de gênero e queer, que têm mais visibilidade do que os estudos sobre bissexualidade. As estudiosas da bissexualidade bebem desses outros campos, mas essa é uma via de mão única. A aparência de ineditismo em uma pesquisa sobre bissexualidade é um sintoma da invisibilidade e do apagamento bissexual (YOSHINO, 2000), que se manifesta inclusive na academia, tendo em vista o desconhecimento generalizado de um importante campo de estudos de gênero e sexualidade que já tem mais de três décadas de acúmulo. Valeria perguntar, assim, por que os trabalhos mais influentes sobre bissexualidade não são traduzidos e publicados no Brasil e por que seu acesso é tão difícil, enquanto, comparativamente, o acesso à teoria queer, por exemplo, não é.

Tendo isso em mente, o presente artigo pretende apresentar algumas das contribuições importantes para os estudos da bissexualidade, de forma a contribuir para a divulgação e acesso às discussões relevantes no campo. Ele está

${ }^{2}$ As reflexões realizadas neste artigo têm como base minha dissertação de mestrado, em especial o primeiro capítulo (MONACO, 2020).

3 Agradeço especialmente ao Grupo Amazônida de Estudos sobre Bissexualidade (GAEBI) pelas reflexões e trocas a esse respeito. 
dividido em três seções. A primeira apresenta o início da organização política bissexual em movimentos autônomos, que influenciou a produção teórica sobre bissexualidade, dando origem às chamadas epistemologias bissexuais. A segunda seção discute a posição da bissexualidade como um suposto terceiro elemento na díade homo/heterossexualidade. Nela, argumentarei que a bissexualidade tem sido imaginada como uma sexualidade de fronteira, com elementos de pertencimento a ambas as esferas, e agindo como um limite simbólico entre elas, que tanto pode delimitar sua separação quanto torná-la mais permeável. Na terceira seção, discuto os usos da categoria "monossexualidade" por teóricas e ativistas bissexuais, que cria uma separação entre termos opostos: bissexualidade e monossexualidade. A partir dos argumentos apresentados, concluo que a bissexualidade não estabeleceu um espaço próprio, mas circula pelos demais, ainda que como um outro incômodo.

\section{Políticas e epistemologias bissexuais}

Nos anos 1960, surgiram, em sociedades ocidentais, movimentos organizados em torno de identidades de gênero, raça e sexualidade. Os movimentos gays e lésbicos foram essenciais na construção de identidades sexuais, procurando desconstruir a economia da heterossexualidade e a taxonomia de espécies sexuais. Ele desafiava não apenas a psiquiatria e a patologização da homossexualidade, mas a própria divisão entre masculino e feminino, hétero e homossexual, reivindicando um mundo sem essas distinções (ANGELIDES, 2001). De acordo com Angelides (2001), a bissexualidade foi usada nesse período como conceito desconstrutivo para esse propósito, mas foi negada por esses movimentos como uma possibilidade no tempo presente, reduzida a uma dimensão utópica.

Em meados dos anos 1970, a oposição hétero/homossexualidade se fortaleceu e o gênero permaneceu como elemento central na sexualidade. Por sua vez, a identidade e política bissexual, assim como o queer, surgiu a partir dos movimentos gays, lésbicos e feministas dos anos 1970, e a partir da insatisfação com as políticas identitárias (CALLIS, 2009). Assim, na década de 1970 começaram a surgir, principalmente nos Estados Unidos, grupos de ativismo e apoio bissexuais. A bissexualidade, enquanto identidade sexual distinta, foi construída (VAN ALPHEN, 2016).

Até esse momento, a bissexualidade havia sido objeto de estudos e reflexões de diversos campos, como a biomedicina, a sexologia e a psicanálise 4 . Para Steven Angelides (2001), a bissexualidade foi central para a construção das categorias binárias de sexo e gênero. Nesse sentido, as representações da sexualidade funcionam não como uma estrutura diádica, mas como uma tríade, na qual a bissexualidade é parte da estrutura, agindo como elemento epistemológico central nesses discursos. Mas ela é sempre negada no tempo presente. Angelides (2001) argumenta que a bissexualidade é vista de uma perspectiva evolucionista, colocada sempre numa etapa anterior a um processo evolutivo, seja biológico ou psíquico, ou em um futuro utópico.

Com o advento da AIDS5, a bissexualidade se tornou alvo de vários estudos nos anos 1980 e 1990 (STORR, 2002). A atenção de epidemiologistas se voltou para bissexuais, ou, melhor dizendo, para homens que se colocavam

4 Para uma reflexão mais detalhada sobre estes estudos, ver Angelides (2001; 2006) e Storr (2002). Para uma revisão dessa literatura, ver Monaco (2020).

5 Sigla em inglês da Síndrome da Imunodeficiência Adquirida (Acquired Immunodeficiency Syndrome) ou SIDA, causada pelo Vírus da Imunodeficiência Humana (HIV). 
publicamente como heterossexuais, mas que tinham práticas bi ou homossexuais. Havia uma preocupação de que esses homens agiriam como uma ponte de infecção - a chamada "ponte bissexual" - espalhando HIV/AIDS de comunidades gays para a população heterossexual. No centro dessa preocupação estava o estereótipo do homem bissexual enrustido, que faz sexo desprotegido casual, contrai HIV e o transmite para sua esposa, presumivelmente heterossexual e sem suspeitas da "real" sexualidade do marido. Pesquisas sobre HIV e saúde sexual de homens bissexuais foram frequentes nos anos 1990, levantando questões sobre como levar materiais sobre saúde sexual para homens bissexuais. Isso teve efeitos importantes em termos de expectativas e preconceitos sobre a transmissão do HIV, e os conhecimentos sobre bissexualidade.

Conforme Clare Hemmings (2002a), no final dos anos 1980 e início dos anos 1990, há um aumento tanto nas campanhas por visibilidade bissexual quanto em trabalhos publicados. Se antes a bissexualidade era estudada desde uma perspectiva médica e epidemiológica, agora ativistas e teóricas bissexuais passavam a escrever cada vez mais sobre si mesmas, sobre experiências, ativismo e política bissexuais. Acompanhando o aumento nas campanhas de visibilidade bissexual nos Estados Unidos (HEMMINGS, 2002a), desenvolveu-se um campo teórico sobre este tema.

Nesse contexto, emergem as chamadas epistemologias bissexuais. Merl Storr (2002) explica que o conjunto de trabalhos que ela chama de epistemologias bissexuais é inspirado na percepção, por parte de bissexuais, de não pertencerem a nenhum lado da dicotomia hétero/homossexual, que organiza os entendimentos da sexualidade moderna. Intelectuais bissexuais, assim, passam a desconfiar das categorias heterossexual e homossexual, ou mesmo da categorização em si. A bissexualidade é tomada como um conceito epistemológico com grande potencial de transformação, enquanto a ideia de uma identidade bissexual é questionada e criticada.

Elizabeth Lewis (2012) argumenta que as epistemologias bissexuais apresentam influências da teoria queer, sendo, em sua maioria, publicados depois de Gender Trouble (BUTLER, 2016 [1990]) e Epistemology of the Closet (SEDGWICK, 1990), livros canônicos da teoria queer (LEWIS, 2012). Lewis anota que tanto a teoria queer quanto as epistemologias bissexuais podem ser mobilizadas para desestabilizar o binário heterossexual/homossexual, mas a principal diferença é que as epistemologias bissexuais colocam a bissexualidade como ponto de partida para essa desconstrução, enquanto a teoria queer não prescreve um ponto de partida específico. De acordo com Lewis (2012), foi com as epistemologias bissexuais que diversas teóricas e teóricos começaram a problematizar a bissexualidade e se concentrar principalmente na questão da categorização e da definição da bissexualidade, bem como nas suas possibilidades políticas e epistemológicas.

Ainda de acordo com Lewis (2012), uma das autoras mais influentes deste período é Marjorie Garber, com seu livro Vice-Versa: Bissexualidade e o erotismo na vida cotidiana (GARBER, 1997), publicado originalmente em 1995. Nesse livro, Garber argumenta que a bissexualidade não deveria ser entendida em relação aos binários heterossexualidade/homossexualidade, homem/mulher e masculinidade/feminilidade, e sim romper com essas oposições. Para ela, a bissexualidade representa a própria natureza do erotismo. Ela seria inerentemente transgressora e mostraria a impossibilidade de categorizar a sexualidade humana. Assim, Garber apresenta uma crítica ao identitarismo e à essencialização das categorias de sexualidade: 
Resumindo, não existe um "realmente". A questão de saber se alguém era "realmente" hetero ou "realmente" gay deixa de reconhecer a natureza da sexualidade, que é fluida, não-fixa, uma narrativa que muda com o tempo, em vez de uma identidade fixa, ainda que complexa. A descoberta erótica da bissexualidade é o fato de ela revelar que a sexualidade é um processo de crescimento, transformação e surpresa, e não um estado de ser conhecível e estável. (GARBER, 1997: 73)

Garber considera que a bissexualidade ameaça as dualidades e desfaz a orientação sexual - e, nesse sentido, não poderia ser uma identidade. A bissexualidade mostraria a fluidez da sexualidade e a impossibilidade de fixá-la em uma identidade. De fato, Elisabeth Däumer (2002) considera as duas dimensões da bissexualidade - identitária e epistemológica - incompatíveis, e as vantagens de uma não poderiam ser aproveitadas enquanto a outra é perseguida. Isso porque as identidades precisam ser fixas, e o potencial epistemológico transformador da bissexualidade reside justamente em sua ambiguidade (STORR, 2002). Assim, a bissexualidade deveria ser tomada como um ponto epistemológico a partir do qual seria possível desconstruir as estruturas dicotômicas de gênero e sexualidade. É por ser ambígua que a bissexualidade possibilita perceber as contradições das identidades.

Rejeitando uma oposição binária entre homossexualidade e heterossexualidade, Garber (1997) propõe pensar a sexualidade em geral e a bissexualidade especificamente em um modelo tridimensional, como uma fita de Möbius, que incorpora as dimensões de dentro e fora. Trata-se de uma imagem onde as duas pontas de uma fita são ligadas, com uma meia torção, de modo que a fita passa a ter apenas uma face, e não duas: “Assim, não temos um ‘terceiro' espaço, e sim um espaço que incorpora os conceitos de 'dois', 'um' e 'três”' (GARBER, 1997: 31). Ela propõe, com isso, pensar a sexualidade como uma superfície contínua. A fita de Möbius, como a bissexualidade, na concepção de Garber, dá a sensação de estar simultaneamente dentro e fora; ou melhor, não está dentro nem fora: ela mesma cria o "dentro" e o "fora".

Outra referência importante desse movimento nos anos 1990 é Jo Eadie, que se volta para a exclusão de bissexuais dos discursos e das comunidades gays e lésbicas nos Estados Unidos e Reino Unido. Para Eadie, essa exclusão seria um sintoma de uma questão epistemológica: a homossexualidade se distingue da heterossexualidade, e essa distinção pressupõe a exclusão da bissexualidade. Reconhecendo a bissexualidade, a divisão entre hétero e homossexualidade se tornaria instável. Entretanto, para Eadie (2002) essa instabilidade é positiva, servindo para romper com a dicotomia hétero/homossexualidade e transformar o modo pelo qual a sexualidade é organizada (STORR, 2002). Uma política bissexual, assim, não se pautaria na construção de um terceiro termo para a díade hétero/homossexual, mas no próprio desmantelamento do aparato que mantém essa divisão.

\section{Uma sexualidade de fronteira}

Uma questão frequente na literatura sobre a bissexualidade diz respeito a seu lugar em relação à homossexualidade e à heterossexualidade. Pode-se dizer que a heterossexualidade e a homossexualidade se estabeleceram amplamente enquanto categorias opostas, mas a bissexualidade não. Ela é comumente imaginada ocupando um não-lugar entre as outras duas, entre dois espaços nitidamente marcados e separados. Por isso, Jo Eadie identifica a bissexualidade como uma posição miscigenada: de um lado, ela levanta a necessidade de uma política 
sexual que compreenda desejos pelo "sexo oposto"; do outro, inclui, em si mesma, uma mistura de orientações supostamente incompatíveis (EADIE, 2002: 133).

As bissexualidades, ao fugirem à lógica binária da dicotomia homossexual/heterossexual, colocam-se em um entre-lugar (BHABHA, 1998), que, para as epistemologias bissexuais, foge à fixidez identitária. Enquanto prática, ela é um ponto de encontro entre a homossexualidade e a heterossexualidade, que, ao mesmo tempo, não é nem uma, nem outra, mas que sobrepõe as duas. Homi Bhabha (1998) descreve os entrelugares a partir dos processos de articulação de diferenças culturais que permitem a sobreposição e o deslocamento de domínios da diferença. Os entrelugares, para Bhabha, propiciam a elaboração de estratégias de subjetivação que por sua vez desencadeiam novos signos de identidade e possibilitam novos postos de colaboração e contestação. A reivindicação de uma identidade bissexual baseia-se na mesma lógica de definição - e fixação - do sujeito por meio do gênero de seu objeto de desejo/afeto, ao passo que rompe com a lógica de exclusividade inerente a ela. Para pensar essa posição da bissexualidade, Jo Eadie (2002) usa a noção de hibridismo, de Bhabha, que quebra a dualidade de eu/outro e dentro/fora - como na figura da fita de Möbius proposta por Garber. O hibridismo, para Eadie, permite incorporar a noção de alteridade à bissexualidade, sem um rompimento radical.

Assim como a noção de hibridismo, a figura da mestiza, de Gloria Anzaldúa (2005) também pode ser mobilizada para refletir sobre a posição da bissexualidade entre a heterossexualidade e a homossexualidade. Para Anzaldúa, a posição da mestiza seria uma posição privilegiada do ponto de vista epistemológico por ser, em si, um lugar de fronteira. A mestiza, de forma semelhante ao híbrido de Bhabha, aprenderia a equilibrar as diferentes culturas e a incluir ao invés de excluir. Como mestiza, Anzaldúa defende, ela se encontra ao mesmo tempo sem pertencimento a lugar algum e pertencendo a todos os lugares e culturas. Sem pertencimento porque ela não é por completo nenhuma das partes que a compõem, mas pertence a todos os lugares devido à multiplicidade de lugares que se fazem presentes nela. Nesse sentido, a mestiza rompe com o pensamento binário de identidades ao se colocar nos entre-lugares da diferença.

\begin{abstract}
Borders are set up to define the places that are safe and unsafe, to distinguish us from them. A border is a dividing line, a narrow strip along a steep edge. A borderland is a vague and undetermined place created by the emotional residue of an unnatural boundary. It is in a constant state of transition. The prohibited and forbidden are its inhabitants. Los atravesados live there: the squint-eyed, the perverse, the queer, the troublesome, the mongrel, the mulato, the half-breed, the half dead; in short, those who cross over, pass over, or go through the confines of the 'normal'. (ANZALDÚA, 1999: 25, grifos da autora)
\end{abstract}

Se a fronteira define os espaços e separa o "nós" do "eles", aquelas que se localizam na fronteira encontram-se indefinidas. A bissexual, nesse sentido, é uma atravessada, nem de um lado, nem de outro, nem hétero, nem homossexual. A bissexualidade tem elementos da heterossexualidade e da homossexualidade, ela está nos dois lugares, porém, não pertence a nenhum deles. Ela é a fronteira entre heterossexualidade e homossexualidade, é a linha divisória na dicotomia hétero/homo que define e separa esses dois espaços, mas é também a prova viva da permeabilidade entre eles.

Não é incomum que por ocuparem essa posição de fronteira, bissexuais sejam acusadas de estarem "em cima do muro" ou indecisas. Inspirada em Eve Sedgwick e sua Epistemologia do Armário (SEDGWICK, 1990), Maria Pramaggiore formula suas Epistemologias do Muro (Epistemologies of the Fence) utilizando a imagem do muro como uma metáfora para os entendimentos da bissexualidade 
(STORR, 2002). O muro seria um local intermediário, de indecisão, que divide e demarca locais. Para Pramaggiore (2002), estar em cima do muro é uma recusa a fórmulas restritivas e binárias de gênero, que associam um gênero a um único objeto de escolha sexual generificado. As epistemologias bissexuais, para ela, permitem reenquadrar esses regimes de desejo. O muro seria uma estrutura permeável, contrária a estruturas exclusivas. Localizado entre dois espaços, o muro ocupa uma posição de visibilidade e invisibilidade. Esse espaço tem sido pensado a partir de modelos de identidade racial, interracialidade e identidades multirraciais (PRAMAGGIORE, 2002), como mostra Yasmin Prabhudas em sua analogia entre bissexualidade e mestiçagem (mixed-race):

To be bisexual is to be both gay and straight. It means that we benefit from fulfilling relationships with people of both sexes.

To be mixed-race is to be both black and white. It means that we benefit from the richness of two different cultures. (PRABHUDAS, 2002: 151)

Para Prabhudas (2002), tanto bissexuais quanto pessoas mestiças são colocadas em um entre-lugar. Isso faz com que esses grupos encontrem dificuldades semelhantes. Entretanto, há também um efeito positivo: tanto bissexuais quanto mestiças, para Prabhudas, têm a capacidade de unir os espaços separados de homo/hétero e negra/branca, de estabelecer um diálogo entre os dois grupos. Em uma direção semelhante, Amanda Udis-Kessler (2015) afirma que bissexuais não estão em cima de muro, mas que constroem pontes entre as esferas hétero e homossexual. Bissexuais, portanto, deveriam unir-se às lutas de movimentos de gays e lésbicas e agir como construtoras de pontes.

Reconhecendo ou não o potencial transformador da bissexualidade em sua posição privilegiada entre-lugares, resta a questão de que, apesar de as sujeitas bissexuais terem acesso aos dois lugares, não necessariamente elas são bem-vindas neles. Clare Hemmings (2002b) mostra que, mesmo aparecendo ocasionalmente em trabalhos pós-modernos e de teoria queer, a bissexualidade nunca foi levada a sério teoricamente. Na política, nos Estados Unidos e no Reino Unido, a bissexualidade também foi marginalizada. De fato, Hemmings (1993 apud FARRIMOND, 2012) contesta a metáfora da ponte utilizada por Udis-Kessler (2015), Prabhudas (2002), Hélène Cixous (2002), e outras autoras, pois ela reforçaria a realidade da heterossexualidade e da homossexualidade, em detrimento da bissexualidade.

Para Hemmings (2002a) a metáfora da ponte reproduz o entendimento da bissexualidade como abstrata ou como uma fase passageira, pois ela se torna real apenas em contextos heterossexuais ou homossexuais. Conceituar a bissexualidade como ponte retira seu caráter de sexualidade em si mesma: "No one stays on a bridge for long" (HEMMINGS, 2002a: 3). Ao invés disso, Hemmings (1993 apud FARRIMOND, 2012) utiliza a metáfora da agente dupla: se a ponte liga os mundos hétero e homossexual, a agente dupla, além de ligar, perturba a própria fronteira que supostamente os separa. Para Katherine Farrimond (2012) a metáfora da agente dupla permite notar como a bissexualidade gera ansiedades e dúvidas com relação às motivações e lealdades da sujeita bissexual - no caso analisado por ela, em personagens de filmes com comportamento bissexual do tipo femme fatale - colocando a mulher bissexual como suspeita e perigosa.

Espaços especificamente bissexuais são raros e, quando existem, costumam ser limitados e temporários (HEMMINGS, 2002a). Mas, por isso mesmo, podese dizer que todos os espaços são virtualmente bissexuais. É por estar em todos os lugares, mas ao mesmo não pertencer completamente a nenhum deles que a bissexualidade é formulada como um entre-lugar, um não-lugar, um muro 
provisório, uma fronteira ou uma ponte que liga dois lugares distintos, sem nunca se tornar seu próprio lugar. Mas ela é também um obstáculo, um outro incômodo e imprevisível que, não tendo um lugar devido, está sempre no meio do caminho, circulando nos lugares "indevidos".

A bissexual, assim, não é apenas uma agente dupla, como propõe Hemmings. É também uma agente secreta: ela pode ser qualquer pessoa, estar em qualquer lugar. Não há como garantir que alguém não é bissexual ou que um espaço é exclusivamente gay, lésbico ou heterossexual. A bissexualidade penetra todos os espaços, colocando em xeque as fronteiras rígidas entre homossexualidade e heterossexualidade. Por esse motivo, é muitas vezes entendida como uma sexualidade perigosa. E, para as epistemologias bissexuais, é justamente nesse perigo que reside seu poder.

\section{Outras fronteiras possíveis: bissexualidade versus monossexualidade}

Com a emergência do ativismo e das teorias bissexuais, surge uma nova polarização, a partir de um outro que se opõe à bissexualidade. Me refiro à oposição bissexual/monossexual e à ideia de monossexualidade ${ }^{6}$. Por não se encaixar em nenhum dos lados da oposição hétero/homossexual, a bissexualidade começa a ser pensada através de outra oposição que, curiosamente, coloca tanto a heterossexualidade quanto a homossexualidade no mesmo lado: o lado da sexualidade direcionada a um único objeto de desejo generificado. Lani Ka'ahamanu e Loraine Hutchins definem monossexual como: "A term used for both heterosexuals and homosexuals - i.e., all people who love only one gender and take for granted the sexual dichotomy set up by the patriarchy. Bisexuality calls this system of categories and divisions into question" (KA'AHAMANU, HUTCHINS, 2015: 7030). Tal definição posiciona a bissexualidade como uma forma de romper com as categorias binárias supostamente reproduzidas por todos os "monossexuais".

Um dos usos da ideia de monossexualidade é mostrar que existem interesses comuns a heterossexuais e homossexuais no apagamento da bissexualidade. Kenji Yoshino (2000) refere-se ao apagamento sistemático da bissexualidade como um contrato epistêmico entre heterossexuais e homossexuais. Para Yoshino, esses dois grupos utilizam as mesmas estratégias para o apagamento da bissexualidade: apagamento de classe, apagamento individual e deslegitimação. Essas estratégias fundamentam-se nos interesses em comum que monossexuais têm no apagamento bissexual. Aqui quero destacar um deles, que diz respeito à estabilização da orientação sexual, seja ela heterossexual ou homossexual. A bissexualidade ameaça essa estabilidade porque impede que os monossexuais "provem” sua orientação sexual, na medida em que, como explica Yoshino (2000), heterossexuais só podem "provar" que são heterossexuais pelo seu desejo pelo "sexo oposto"7 - isto é, não podem provar a ausência de desejo pelo "mesmo sexo". Assim, a heterossexualidade - ou qualquer identidade monossexual - não pode ser comprovada definitivamente se a bissexualidade for reconhecida como possibilidade.

Aqui percebe-se o perigo da bissexualidade como agente secreta, conforme a caracterizei no tópico anterior. Por poder se infiltrar silenciosamente em todos os

\footnotetext{
${ }^{6} \mathrm{O}$ termo "monossexual" foi usado anteriormente por sexologistas no sentido de heterossexualidade ou homossexualidade exclusiva (STORR, 2002), mas me refiro aqui aos usos mais recentes do termo por teóricas e ativistas bissexuais.

7 Aqui, Yoshino (2000) utiliza as expressões mesmo sexo (same-sex) e sexo oposto (cross-sex), pois entende bissexualidade como atração por dois sexos e não por dois (ou mais) gêneros, como é mais comum no ativismo bissexual brasileiro.
} 
lugares, a bissexualidade impede a constituição definitiva de um domínio monossexual pela exclusão de seu oposto também monossexual. Dito de outro modo, o espectro da bissexualidade faz com que qualquer identidade monossexual seja facilmente questionável, uma vez que a linha divisória entre elas se torna permeável. Nesse sentido, a bissexualidade precisaria ser apagada para que a heterossexualidade e a homossexualidade não sejam alvo de desconfiança. Excluindo a possibilidade de desejar mais de um sexo ou gênero, o desejo heterossexual e o homossexual tornam-se mutuamente exclusivos e as respectivas orientações sexuais mais facilmente delimitadas. Assim, resolve-se o problema da impossibilidade de comprovar a ausência de atração, já que a atração por um gênero passa a ser entendida como prova suficiente da não atração por outros.

Para Amanda Udis-Kessler (2015), grande parte da bifobia praticada por gays e lésbicas é uma expressão da crise de significado que a bissexualidade representa para o discurso sexual estadunidense, que considera a sexualidade uma essência. A negação da existência da bissexualidade por parte de homossexuais, para UdisKessler, é, na verdade, uma afirmação de sua própria existência: "Behind the painful lesbian and gay biphobia which we have experienced is a poignant cry for a self; 'you don't exist' means 'I do exist'” (UDIS-KESSLER, 2015: 6717). Para Yoshino (2000), a negação é importante para vincular os homossexuais a uma comunidade e estabelecer uma identidade para si.

No caso de heterossexuais, Udis-Kessler (2015) argumenta que a bissexualidade também pode causar uma crise de significado ao aproximá-los dos homossexuais. A bissexualidade representa, assim, uma ameaça ao dualismo hétero/homossexual. Nesse caso, a negação da existência bissexual tem um significado diferente, de separação dos homossexuais: “The comment 'you don't exist' really means something else, namely, 'I'm not gay"' (UDIS-KESSLER, 2015: 6759). Nesse sentido, a rejeição à bissexualidade, se dá por motivos diferentes, mas, em ambos os casos, centra-se mais na homossexualidade do que na bissexualidade em si mesma.

A categoria monossexual pode ajudar a explicar diversas atitudes e concepções hostis à bissexualidade praticadas por grupos aparentemente muito diversos e sem interesses em comum. Mas algumas autoras como Hemmings (2002a) criticam seu uso. Para ela, chamar todos os não-bissexuais de monossexuais ocultaria as diferenças entre gays/lésbicas e heterossexuais, igualando as relações de poder que existem entre esses dois grupos. Ela argumenta que as diferenças sociais, econômicas e de definição, entre lésbicas/gays e heterossexuais são convenientemente ignoradas nos usos da categoria "monossexual". Entretanto, autores como Yoshino (2000) fazem distinções importantes entre homossexuais e heterossexuais. Diferente do que a crítica de Hemmings leva a crer, Yoshino leva em consideração as diferenças sociais entre gays, lésbicas e heterossexuais (embora não entre homens e mulheres heterossexuais) em sua explicação dos fundamentos do interesse dos dois grupos no apagamento bissexual, como explicitado acima.

Para Amber Ault (2002), defender a bissexualidade como identidade em oposição à categoria da monossexualidade significa reinscrevê-la num enquadramento binário. Isso porque os discursos da bissexualidade em oposição à monossexualidade deslocam a bissexualidade da margem ao centro, ao mesmo tempo em que constituem pessoas heterossexuais e gays/lésbicas como relativamente depravadas. Com isso, a polarização, ao invés de ser eliminada como sugeririam as epistemologias bissexuais, apenas muda para a divisão monossexual/bissexual, que para Ault (2002) seria mutuamente exclusiva: ou se é monossexual, ou 
bissexual. Acredito, entretanto, que a ideia de monossexualidade, ou mesmo monossexismo, é útil para explicar não apenas o apagamento ou relativa invisibilização da bissexualidade, mas também a classificação da sexualidade dos sujeitos com base no sexo/gênero da parceria sexual momentânea.

Nesse sentido, creio ser mais proveitoso entender a monossexualidade não pela oposição entre bissexuais e héteros/gays/lésbicas, mas pela oposição entre a dicotomia homo/hétero e o terceiro excluído, ou seja, ao próprio sistema classificatório monossexual, segundo o qual ou se é heterossexual ou se é homossexual, estando excluídas as possibilidades de ser os dois, nenhum ou outro. A ideia de monossexualidade é útil, não porque heterossexuais, gays e lésbicas sejam iguais, mas porque ela mostra a posição da bissexualidade como um outro, inerente à oposição hétero/homossexual. Embora diferentes e hierarquizadas, essas duas posições se colocam como opostas, reconhecendo uma à outra e externalizando a bissexualidade que se torna impensável e invisível.

Dito isso, reconheço, entretanto, que há limites no uso da categoria monossexual. Um deles diz respeito à ideia recorrente de que as categorias binárias de gênero e sexualidade são reproduzidas pelos sujeitos monossexuais. Ela não leva em consideração diferentes configurações de gênero e de desejo que poderiam levar a sexualidades passíveis de descrever como "monossexuais". Por isso, é perigoso assumir que a bissexualidade ocupa (a única) posição revolucionária ou disruptiva em si mesma. Assim, concordo com a crítica de Clare Hemmings (2002a) à tendência de postular uma natureza transgressora à bissexualidade, presumida como autoevidente e necessariamente desafiadora de oposições binárias.

Apesar de reconhecer as potencialidades da monossexualidade enquanto categoria de análise, portanto, reconheço também a necessidade de resistir à essencialização da bissexualidade na oposição mono/bissexual, bem como à presunção da bissexualidade como uma posição privilegiada para o rompimento das relações de gênero e sexualidade baseadas em oposições binárias. Como mostra Angelides (2001), ao contrário de ser externa a tais categorizações, a bissexualidade agiu em diversos momentos como um elemento central, embora invisível, para sua manutenção.

\section{Considerações finais}

Neste artigo, procurei demonstrar que a bissexualidade é um tema potente para pensar sujeitos, desejos e epistemologias outras, descoladas da heteronorma. Ela permite fugir do pensamento dualista que opõe hierarquicamente heterossexualidade e homossexualidade como as duas únicas opções viáveis. A partir da bissexualidade, é possível pensar o afeto e o desejo por meio de outros signos para além do sexo/gênero.

Nessa direção, argumentei que as chamadas epistemologias bissexuais constroem a bissexualidade como um princípio desarticulador dos binarismos de gênero e sexualidade. Entretanto, Clare Hemmings (2002a) critica essa perspectiva que postula a bissexualidade como posição privilegiada sem especificar sua natureza e seus limites críticos. Nesse sentido, a bissexualidade, e seu desafio às oposições hétero/homossexuais são vistas frequentemente de forma essencializada. Hemmings chama atenção para a necessidade de produzir teoria bissexual engajada com a complexidade e sofisticação das experiências de bissexuais cujas múltiplas localizações não podem ser entendidas simplesmente como transgressoras. Por esse motivo, é imprescindível ter em vista as formas como sujeitas bissexuais 
entendem suas práticas, organizam suas experiências e constroem uma subjetividade bissexual. As possibilidades políticas da bissexualidade não são dadas a priori, mas são construídas coletivamente por essas sujeitas.

No Brasil, os estudos sobre bissexualidades ainda são incipientes, mas vêm crescendo nos últimos anos, principalmente em pesquisas que se voltam às relações entre bissexuais e organizações caracterizadas como LGBT8, ou de gays e lésbicas (CAVALCANTI, 2007; LEWIS, 2012; LEÃO, 2018). Portanto, é essencial que o acúmulo teórico sobre este tema se torne acessível a jovens pesquisadores e pesquisadoras que têm se dedicado a ele - seja para embasar teoricamente projetos de pesquisa, seja para contestar e contrapor estes textos que se referem a realidades diferentes da brasileira.

Não se trata, pois, de uma aplicação acrítica dessas reflexões sobre bissexualidade a contextos do chamado sul global. Ao contrário, é preciso compreender que mesmo a separação da sexualidade humana em duas espécies distintas, negando todas as outras possibilidades, é também uma ferramenta colonial que afeta não apenas bissexuais, pansexuais e assexuais, mas todos os sujeitos subalternizados que não condizem com o ideal de homem branco europeu e heterossexual. Angelides (2001) mostra como a própria ideia de bissexualidade foi usada pelo pensamento psicomédico para explicar a diferença e hierarquizá-la, colocando-a como um ponto de partida biológico ao qual mulheres e pessoas racializadas permaneciam mais próximas, ao passo que o homem branco completava sua transição - de uma natureza bissexual para uma cultura sexualmente diferenciada.

A multiplicidade de formas de definir, mobilizar politicamente e teorizar a bissexualidade revela a importância de adotar uma perspectiva que leve em conta as pluralidades e diversos marcadores sociais que a interseccionam, evitando universalismos das categorias de gênero e sexualidade, como propõe Oyèrónké Oyěwùmí (2004). Para pensar as bissexualidades no Brasil, faz-se necessário ter em vista os sentidos locais da categoria "bissexualidade", recusando o pensamento eurocentrado, como sugere Aníbal Quijano (2009). Mas também é importante conhecer as discussões teóricas que já existem sobre o tema, especialmente em contextos em que este campo começou a se desenvolver apenas recentemente, como no Brasil.

Vimos que a bissexualidade é frequentemente entendida como um espaço de fronteira ou linha divisória que separa os limites das categorias estabelecidas de sexualidade - isto é, heterossexualidade e homossexualidade. Entretanto, esse lugar ambíguo se torna um perigo simbólico para as outras categorias. Tendo seu espaço próprio negado, a bissexualidade penetra os demais domínios. Assim, qualquer espaço pode ser bissexual, embora nenhum o seja por completo - e justamente por isso. A bissexualidade permanece ocupando uma posição de exterioridade abjeta (BUTLER, 2016) em quase todos os espaços, como uma intrusa que nem sempre é reconhecível num primeiro momento, uma agente secreta. Ela não se encontra fora da heterossexualidade e da homossexualidade, e por isso pode ser interpretada como perigosa: porque adentra silenciosamente, por vezes escondida, podendo revelar uma alteridade, um outro, no interior de uma aparente normatividade ou de um "nós" supostamente homogêneo.

Pesquisas nacionais e estrangeiras têm mostrado que espaços bissexuais são escassos. Mas mais do que muros, pontes ou fronteiras, vejo bissexuais como sujeitas nômades, sem um espaço fixo para si, sempre circulando em diferentes 
espaços das estruturas binárias da sexualidade. O espaço bissexual é o próprio movimento.

Recebido em 20 de janeiro de 2021.

Aprovado em o3 de maio de 2021.

\section{Referências}

ANGELIDES, Steven. A history of bisexuality. Chicago: The University of Chicago Press, 2001.

ANGELIDES, Steven. Historicizing (Bi)Sexuality. Journal of Homosexuality, 52 (1-2): 125-158, dez. 2006.

ANZALDÚA, Gloria. Borderlands/La Frontera: The new Mestiza. San Francisco: Aunt Lute Books, 1999.

ANZALDÚA, Gloria. La conciencia de la mestiza/Rumo a uma nova consciência. Estudos Feministas, 13 (3): 704-719, 2005.

AULT, Amber. "Amber Ault: Ambiguous Identity in an Unambiguous Sex/Gender Structure: The Case of Bisexual Women (1996)". In: STORR, Merl (ed.). Bisexuality: A Critical Reader. Ebook: Taylor \& Francis E-library, 2002. pp. 167185.

BHABHA, Homi. O Local da Cultura. Belo Horizonte: Editora UFMG, 1998.

BUTLER, Judith. Problemas de gênero: Feminismo e subversão da identidade. Rio de Janeiro: Civilização Brasileira, 2016.

CALLIS, April S. Playing with Butler and Foucault: Bisexuality and Queer Theory. Journal of Bisexuality, 9 (3-4): 213-233, 2009.

CAVAlCANTI, Camila Dias. Visíveis e invisíveis: Práticas e identidade bissexual. Dissertação de Mestrado, Sociologia, Universidade Federal de Pernambuco, 2007.

CIXOUS, Hélène. "Hélène Cixous: Extract from The Laugh of the Medusa (1975)". In: STORR, Merl. Bisexuality: A Critical Reader. Ebook: Taylor \& Francis E-library, 2002. pp. 189-192.

DÄUMER, Elisabeth. "Elisabeth D. Däumer: Extract from Queer Ethics; or, the Challenge of Bisexuality to Lesbian Ethics (1992)". In: STORR, Merl. Bisexuality: A Critical Reader. Ebook: Taylor \& Francis E-library, 2002. pp. 152-161. 
EADIE, Jo. "Jo Eadie: Extracts from Activating Bisexuality: Towards a Bi/Sexual Politics (1993)”. In: STORR, Merl. Bisexuality: A Critical Reader. Ebook: Taylor \& Francis E-library, 2002. pp. 119-137.

FARRIMOND, Katherine. 'Stay Still So We Can See Who You Are': Anxiety and Bisexual Activity in the Contemporary Femme Fatale Film. Journal of Bisexuality, 12 (1): 138-154, 2012.

GARBER, Marjorie. Vice-versa: bissexualidade e o erotismo na vida cotidiana. Rio de Janeiro: Record, 1997.

HEMMINGS, Clare. Bisexual spaces: A geography of sexuality and gender. New York: Routledge, 2002a.

HEMMINGS, Clare. "Clare Hemmings: Extract from Locating Bisexual Identities: Discourses of Bisexuality and Contemporary Feminist Theory (1995)". In: STORR, Merl. Bisexuality: A Critical Reader. Ebook: Taylor \& Francis E-library, 2002b. pp. 193-200.

HEMMINGS, Clare. "Resituating the bisexual body". In: J. Bristow \& A. R. Williams (Eds.). Activating theory: Lesbian, gay, bisexual politics. London: Lawrence and Wishart, 1993. pp. 118-138.

KA'AHAMANU, Lani; HUTCHINS, Loraine (Eds). Bi any other name: Bisexual people speak out. Riverdale: Riverdale Avenue Books, 2015 [E-book].

LEÃO, Maria. "Os unicórnios no fim do arco-íris: bissexualidade feminina, identidades e política no Seminário Nacional de Lésbicas e Mulheres Bissexuais”. Dissertação de Mestrado, Saúde Coletiva, Universidade do Estado do Rio de Janeiro, 2018.

LEWIS, Elizabeth Sara. "Não é uma fase": Construções identitárias em narrativas de ativistas LGBT que se identificam como bissexuais. Dissertação de Mestrado, Letras, Pontifícia Universidade Católica do Rio de Janeiro, 2012.

MONACO, Helena. "A gente existe!": ativismo e narrativas bissexuais em um coletivo monodissidente. Dissertação de Mestrado em Antropologia Social, Universidade Federal de Santa Catarina, 2020.

OYĚWÙMÍ, Oyèrónké. "Conceptualizing Gender: The Eurocentric Foundations of Feminist Concepts and the challenge of African Epistemologies. African Gender Scholarship: Concepts, Methodologies and Paradigms". CODESRIA Gender Series. Volume 1, Dakar, CODESRIA, 2004, pp. 1-8.

PRABHUDAS, Yasmin. "Yasmin Prabhudas: Bisexuals and People of MixedRace: Arbiters of Change (1996)". In: STORR, Merl. Bisexuality: A Critical Reader. Ebook: Taylor \& Francis E-library, 2002. pp. 150-151.

PRAMAGGIORE, Maria. "Maria Pramaggiore: Extracts from Epistemologies of the Fence (1996)”. In: STORR, Merl. Bisexuality: A Critical Reader. Ebook: Taylor \& Francis E-library, 2002. pp. 144-149.

QUIJANO, Aníbal. "Colonialidade do poder e classificação social” In: SANTOS, Boaventura de Souza; MENESES, Maria Paula (Orgs.). Epistemologias do sul. Coimbra: Almedina, 2009. pp. 73-117.

SEDGWICK, Eve. Epistemology of the Closet. Berkeley: University of California 
STORR, Merl. Bisexuality: A Critical Reader. Ebook: Taylor \& Francis E-library, 2002.

UDIS-KESSLER, Amanda. "Present tense: Biphobia as a crisis of meaning." In: KA'AHAMANU, Lani; HUTCHINS, Loraine (Eds). Bi any other name: Bisexual people speak out. Riverdale: Riverdale Avenue Books, 2015. Posição. 6633-6820 [E-book Kindle].

VAN ALPHEN, Elise. Erasing Bisexual Identity: The Visibility and Invisibility of Bisexuality as a Sexual Identity in the Dutch Homosexual Movement, 1946-1972. Journal of Homosexuality, 64 (2): 273-288, 2016.

YOSHINO, Kenji. The Epistemic Contract of Bisexual Erasure. Yale Law School Legal Scholarship Repository, 1 (1): 353-461, 2000. 


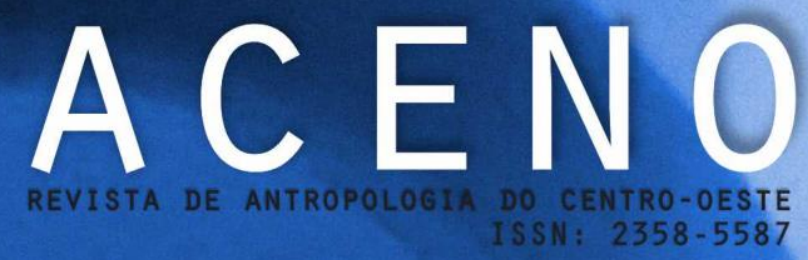

A Aceno recebe em

FLUXO CONTÍNUO,

artigos livres,

resenhas,

ensaios fotográficos,

dossiês (propostas).

Interessados em atuar como

pareceristas

podem realizar seus cadastros no site 